\title{
Phytotoxicity of Clove Oil to Vegetable Crop Seedlings and Nematotoxicity to Root-knot Nematodes
}

\author{
Susan L.F. Meyer ${ }^{1,4}$, Dilip K. Lakshman², Inga A. Zasada ${ }^{1}$, \\ Bryan T. Vinyard $^{3}$, and David J. Chitwood ${ }^{1}$
}

Additional Index wORDs. bio-based nematicide, essential oil, Meloidogyne incognita, nematode management

Summary. Clove oil derived from the clove plant [Syzygium aromaticum (=Eugenia caryophyllata)] is active against various soil-borne plant pathogens and therefore has potential for use as a bio-based pesticide. A clove oil formulation previously found to be toxic to the southern root-knot nematode (Meloidogyne incognita) in laboratory assays was investigated in greenhouse studies for nematode suppression and phytotoxicity on vegetable crops. Phytotoxicity studies were conducted with $0.1 \%, 0.2 \%$, and $0.3 \%$ clove oil applied to soil $0,2,5$, and 7 days before transplant of cucumber (Cucumis sativus), muskmelon (Cucumis melo), pepper (Capsicum annuum), and tomato (Solanum lycopersicum) seedlings. Tomato seedlings were the most sensitive to clove oil. The $0.2 \%$ and $0.3 \%$ clove oil concentrations applied as drenches at transplant ( 0 day) were the most phytotoxic to seedlings of all the tested vegetable species, with only $0 \%$ to $50 \%$ seedling survival. Most of the clove oil concentrations applied as drenches at transplant decreased shoot heights and fresh shoot weights of all seedlings. Some applications of clove oil at $0.2 \%$ and $0.3 \%$, applied 2,5 , or 7 days before transplant also significantly reduced shoot growth, especially of pepper and tomato. Greenhouse experiments evaluating suppression of nematode populations on cucumber were conducted with $0.10 \%, 0.15 \%$, and $\mathbf{0 . 2 0 \%}$ clove oil applied 7 days before transplant. Overall, plants inoculated with nematodes tended to have smaller shoots and heavier roots than plants without nematodes. Effects of clove oil treatments on nematode population densities were inconsistent between the two trials. In Trial $1,0.10 \%$ and $0.15 \%$ clove oil decreased population densities compared with the carrier control. In Trial 2, nematode population densities were lowest in the water and carrier control treatments. The results indicate that, with the tested clove oil formulation and application times, southern root-knot nematode populations would not be consistently reduced with clove oil concentrations that were not phytotoxic to one or more of the tested vegetable crops.

$\mathrm{R}$ oot-knot nematodes (RKN; Meloidogyne spp.) are an economically important pathogen on many agricultural plants and are the

We thank Paula Crowley for laboratory and greenhouse work and figure preparation, and Carol Masler, Grace Pak, Sukla Lakshman, Steven Rogers, and Jeff Quarrick for assistance in the laboratory and greenhouse.

Mention of trade names or commercial products in this publication is solely for the purpose of providing specific information and does not imply recommendation or endorsement by the U.S. Department of Agriculture.

${ }^{1}$ U.S. Department of Agriculture, Agricultural Research Service, Nematology Laboratory, Henry A. Wallace Beltsville Agricultural Research Center (BARC)-West, 10300 Baltimore Ave., Beltsville, MD 20705-2350

${ }^{2}$ US. Department of Agriculture, Agricultural Research Service, Floral and Nursery Plants Research Unit, US National Arboretum, BARC-West, Beltsville, MD 20705-2350

${ }^{3}$ U.S. Department of Agriculture, Agricultural Research Service, Biometrical Consulting Service, BARC-West, Beltsville, MD 20705-2350

${ }^{4}$ Corresponding author. E-mail: Susan.L.Meyer@ars. usda.gov. most commonly reported nematodes on vegetable crops in the United States (Koenning et al., 1999). Because of environmental and other concerns associated with a number of synthetic chemical pesticides, novel, bio-based nematicides could be safe management alternatives for decreasing yield losses caused by this nematode. Plant-derived compounds are a potential source for such nematicides, and essential oils are one type of botanical product that has been studied for management of weeds, arthropods, nematodes, and microbial pathogens. These oils are active against a number of pest organisms, are removed fairly rapidly from the environment, and often have low toxicity to mammals (Bainard et al., 2006).

An essential oil that has been investigated for use as a pesticide against multiple pathogens and pests is derived from the clove plant. Clove oil has demonstrated toxicity to insects and weeds (Bainard et al., 2006; Boyd and Brennan, 2006; Boyd et al., 2006; Isman, 2000; Tworkoski, 2002; Yang et al., 2003), to various microbes, including plant-pathogenic fungi and bacteria (Beg and Ahmad, 2002; Bowers and Locke, 2000, 2004; Cowan, 1999; Dorman and Deans, 2000; Kishore et al., 2007; MontesBelmont and Carvajal, 1998; Walter et al., 1997), and to plant-parasitic nematodes (Chitwood, 2002; Meyer et al., 2008; Pandey and Dwivedi, 2000; Park et al., 2005; Salgado and Campos, 2003a, 2003b; Sangwan et al., 1990). The exact mechanisms of action against plant-parasitic nematodes have not been determined, but may involve the disruption of membranes and changes in membrane permeability. This has been shown to occur with terpenoids, and with clove oil and its main constituent eugenol, when applied to other organisms (Bainard et al., 2006; Cowan, 1999; Tworkoski, 2002).

Because of the known activities of clove oil, we selected it for study as a potential management agent for the southern RKN. The clove oil used in our research was prepared in an aqueous solution with lecithin from soybean (Glycine max) and a nonionic surfactant. In microwell assays, this

\begin{tabular}{llll}
\hline $\begin{array}{l}\text { Units } \\
\text { To convert U.S. } \\
\text { to SI, multiply by }\end{array}$ & U.S unit & SI unit & $\begin{array}{l}\text { To convert SI to U.S., } \\
\text { multiply by }\end{array}$ \\
\hline 10 & $\%$ & $\mathrm{~mL} \cdot \mathrm{L}^{-1}$ & 0.1 \\
29.5735 & $\mathrm{fl} \mathrm{oz}$ & $\mathrm{mL}$ & 0.0338 \\
3.7854 & gal & $\mathrm{L}$ & 0.2642 \\
2.54 & inch $(\mathrm{es})$ & $\mathrm{cm}$ & 0.3937 \\
0.4536 & $\mathrm{lb}$ & $\mathrm{kg}$ & 2.2046 \\
28.3495 & $\mathrm{oz}$ & $\mathrm{g}$ & 0.0353 \\
28,350 & $\mathrm{oz}$ & $\mathrm{mg}$ & $3.5274 \times 10^{-5}$ \\
1 & $\mathrm{ppm}$ & $\mathrm{mg} \cdot \mathrm{kg}^{-1}$ & 1 \\
0.9464 & $\mathrm{qt}$ & $\mathrm{L}$ & 1.0567 \\
$\left({ }^{\circ} \mathrm{F}-32\right) \div 1.8$ & ${ }^{\circ} \mathrm{F}$ & ${ }^{\circ} \mathrm{C}$ & $\left(1.8 \times{ }^{\circ} \mathrm{C}\right)+32$ \\
& & &
\end{tabular}


formulation was toxic to eggs and second-stage juveniles (J2) of RKN (Meyer et al., 2008). It also reduced numbers of $\mathrm{J} 2$ recovered from treated soil. The carrier alone also affected $\mathrm{J} 2$, tending to result in increased $\mathrm{J} 2$ viability (compared with the water control) in the microwell assays, but decreasing J2 recovery from soil (Meyer et al., 2008). The current study was initiated to determine nematicidal activity of this preparation against RKN on plant roots.

While investigating the clove oil formulation as a nematicide, it was also important to determine whether it was harmful to seedlings of vegetable crops. Clove oil, and its primary constituent eugenol, have been reported to have phytotoxic effects (Bainard et al., 2006; Boyd and Brennan, 2006; Boyd et al., 2006; Tworkoski, 2002; Waliwitiya et al., 2005; Walter et al., 2001). In addition, a commercial product sold as a postemergence herbicide, Matran ${ }^{\circledR}$ EC herbicide (EcoSMART Technologies, Alpharetta, GA), is formulated as $50 \%$ clove leaf oil. Therefore, the first goal of our research was to investigate whether there were phytotoxic effects of the clove oil formulation to seedlings of common vegetable crop plants. To this end, the clove oil was tested as a preplant application and at transplanting. The plants selected for the phytotoxicity study were cucumber, muskmelon, pepper, and tomato. The second goal was to determine efficacy of nonphytotoxic clove oil concentrations for suppression of nematode population numbers on plant roots. Clove oil concentrations were selected based on results of the phytotoxicity study, and were then applied to one host plant, cucumber, to study effects on southern RKN population densities.

\section{Materials and methods}

Preparation of Clove oil and OF SOUTHERN RKN. Clove oil (Sigma-Aldrich, St. Louis) was prepared as described by Meyer et al. (2008), in an aqueous carrier solution of $0.25 \%$ L- $\alpha$-phosphatidylcholine (lecithin) from soybean (SigmaAldrich) and a nonionic surfactant Triton X-114 (0.1\%; Rohm \& Haas, Philadelphia). Inoculum of RKN Race 1, originally isolated in Maryland, was grown on 'PA-136' pepper in greenhouse pots. Eggs for green- house experiments were obtained from the roots of 3-month-old pepper plants. To collect eggs, roots were rinsed to remove soil and then immersed in $0.6 \%$ sodium hypochlorite for $1 \mathrm{~min}$ to release the eggs from the egg masses. The eggs were collected on a 500-mesh sieve, rinsed with water, and centrifuged for $3 \mathrm{~min}$ at $447 g_{\mathrm{n}}$. An aqueous sugar solution (454 $\mathrm{g}$ of sugar in $1 \mathrm{~L}$ of water) was added to the eggs and shaken. The eggs were centrifuged again (same time and force), collected on a 500mesh sieve, rinsed in water, stored overnight at $4{ }^{\circ} \mathrm{C}$, and used the next day.

Phytotoxicity to vegetable SEEDLINGS. Seeds of 'Sweetslice' cucumber, 'Hearts of Gold' muskmelon, 'PA 136' pepper, and 'Orange Pixie' tomato were planted into starter mix (Premier Promix ${ }^{\circledR}$; Premier Horticulture, Quakertown, PA), with sowing dates dependent upon the time needed for each seedling type to reach the first true leaf stage by transplant. This was 16 to $19 \mathrm{~d}$ before transplant for cucumber, $19 \mathrm{~d}$ for muskmelon, $30 \mathrm{~d}$ for pepper, and $23 \mathrm{~d}$ for tomato, with the greenhouse maintained at $24^{\circ} \mathrm{C}$ to $29^{\circ} \mathrm{C}$. Natural and supplemental lighting were combined for a 16-h daylength. Soil (composed of 16 sand:9 compost, $\mathrm{v} / \mathrm{v}$ ) was steamed, air dried, and placed into 1-qt sealable plastic bags (385 g of dry soil per bag). Four clove oil concentrations were tested: $0 \%$ clove oil (water control), and $0.1 \%$, $0.2 \%$, and $0.3 \%$ clove oil. To treat the soil, $38.5 \mathrm{~mL}$ of a clove oil concentration was added to $385 \mathrm{~g}$ of soil, moistening the soil to $70 \%$ water holding capacity (WHC) (about 10\% water, weight water per weight soil). Each bag received clove oil at one of four different times: 7,5 , and $2 \mathrm{~d}$ before transplanting (mixed with soil in the plastic bags), and $0 \mathrm{~d}$ before transplant (as a drench at transplant). This resulted in a total of 64 combinations: four seedling types $\times$ four clove oil concentrations $\times$ four application times. At transplant, the soil from each bag was placed into a 250 $\mathrm{mL}$-capacity plastic cup $(8.5 \mathrm{~cm}$ diameter) and one seedling was transplanted into each cup. The plants were arranged in a randomized design and were grown for $8 \mathrm{~d}$ in the greenhouse. Following that time, the numbers of viable plants, shoot heights (from soil to growing tip), and shoot fresh weights (determined on all plant parts above the soil line) were recorded. The experiment was conducted twice, with five seedlings of each plant type per clove oil concentration/application time combination in each of the two trials $(\mathrm{N}=10)$.

SUPPRESSION OF SOUTHERN RKN ON CUCUMBER. Tests of various clove oil concentrations for suppression of RKN populations on plant roots were conducted with 'Sweetslice' cucumber. Greenhouse and soil type conditions were as listed for the "Phytotoxicity" section above. Seeds were planted in the Premier Promix ${ }^{\circledR}$ starter mix and were transplanted 2 weeks later into 4-inch-diameter pots containing soil treated with clove oil or controls. Soil for treatment was first steamed, air-dried, and placed into 1 -qt plastic resealable bags (625.5 g of soil per bag). One week before transplanting, $57.5 \mathrm{~mL}$ of a clove oil concentration (or of a control) and $5 \mathrm{~mL}$ of water with or without $5000 \mathrm{RKN}$ eggs were mixed with the soil in each bag (total liquid per bag resulted in a soil moisture of $70 \%$ of WHC). Clove oil concentrations tested were $0 \%$ clove oil (water control), 0\% (carrier control), and $0.10 \%, 0.15 \%$, and $0.20 \%$ clove oil. After transplant, the pots were arranged in a randomized design. One week later, each plant was fertilized with $3 \mathrm{~g}$ of Osmocote ${ }^{\circledR}$ Plus 15-9-12 (15N-3.9P-10.0K; Scotts-Sierra Horticultural Products, Marysville, OH). Plants were harvested after 5 weeks. At harvest, shoot heights and fresh weights were recorded as described above. Soil and roots were removed from pots, the soil was rinsed from roots, root fresh weights were recorded, and roots were stored at $4{ }^{\circ} \mathrm{C}$ until processing to collect nematode eggs. To collect eggs, roots were cut into pieces with shears, placed in $0.6 \%$ sodium hypochlorite, and ground in a mini-food processor on the low setting for $2 \mathrm{~min}$. The roots and solution were poured onto nested $60 / 80 / 500$-mesh sieves, the eggs were washed with water, collected from the 500-mesh sieve, and stored as aqueous egg suspensions at $4{ }^{\circ} \mathrm{C}$ until counting. Two aliquots from each sample were counted to estimate number of eggs per gram of root.

Statistical METHODS. For the phytotoxicity study, each of the 16 combinations of four clove oil 
concentrations $(0 \%, 0.1 \%, 0.2 \%$, and $0.3 \%)$ and four application times to soil $(2,5$, and $7 \mathrm{~d}$ before transplant, or at transplant) was applied to five plants in each of two trials with vegetable plants. The characteristics of interest were proportion of live plants and shoot heights and weights. Proportion data met analysis of variance (ANOVA) model assumptions without transformation. Consistency between the two trials was examined via a three-way factorial ANOVA using the concentration $\times$ time $\times$ trial effect as the residual term. If none of the effects containing trial (i.e., trial, trial $\times$ concentration, or trial $\times$ time $)$ were significant, a two-way (concentration $\times$ time) factorial ANOVA and a one-way concentration time ANOVA were conducted with subsequent means comparisons. Heterogeneous within concentration $\times$ time variances were modeled using the GROUP = option of the REPEATED statement and false significance in means comparisons minimized by using the ADJUST = Sidak option, in SAS ${ }^{\circledR}$ Proc MIXED (version 9.1; SAS Institute, Cary, NC).

In the study evaluating suppression of RKN on cucumber, data analyzed were shoot heights, shoot and root fresh weights, and mean number of RKN eggs per gram of root. The data were $\log$ transformed $\left[\log _{10}(\mathrm{x}+\right.$ 1)] when necessary to meet the assumptions of the model. Consistency between the two trials was examined via a three-way factorial ANOVA using the concentration $x$ nematode $\times$ trial effect as the residual term. The trials were different and are presented separately. A two-way (concentration $\times$ nematode) factorial ANOVA and a one-way concentration nematode ANOVA were conducted with subsequent means comparisons. Means were compared using Tukey's adjusted for multiple comparisons $(P<0.05)$.

\section{Results}

Phytotoxic effects on percentages of live plants, shoot heights, and fresh weights varied significantly $(\alpha=0.05)$ with plant type, clove oil concentration, and application time, as indicated by the one-way ANOVA. Plant viability was one indicator of phytotoxicity (Table 1). Treatment with the water control $(0 \%$ clove oil) at all application times resulted in $100 \%$ seedling viability, but some clove oil treatments resulted in plant death. Viability in response to clove oil treatment differed among the plant species. Overall, muskmelon and pepper seedling survival was the least affected by the clove oil treatments. Muskmelon seedlings showed $100 \%$ viability in nearly all treatments, and pepper seedling survival was not significantly reduced by any treatment. Tomato seedlings tended to be the most sensitive.

Of the clove oil concentrations tested, only $0.1 \%$ did not significantly affect seedling viability. Application of $0.2 \%$ clove oil at transplant $(0 \mathrm{~d})$ resulted in the death of all of the cucumber and tomato seedlings. In addition, $50 \%$ of the muskmelon and pepper seedlings died with this treatment. Although loss of half of the plants did not result in a statistically significant effect, due to large amongplants variation, this reduction in plant survival is notable from an economical perspective. The results with tomato seedlings were unique in that $0.2 \%$ clove oil applied $7 \mathrm{~d}$ before transplant reduced seedling viability more than $0.2 \%$ clove oil applied $5 \mathrm{~d}$ before transplant. A drench at transplant $(0 \mathrm{~d})$ with $0.3 \%$ clove oil was the most phytotoxic of all the treatments; the decreases in numbers of live plants were significant (compared with water controls) in all crops except pepper.

Phytotoxic effects of various clove oil treatments were also indicated by decreases in shoot heights and fresh weights compared with water controls

Table 1. Effects of clove oil applications on viability of cucumber, muskmelon, pepper, and tomato seedlings. Numbers are the percentage of viable seedlings in each treatment. Seedlings at the one-leaf stage were transplanted into soil that had been treated with clove oil or a water control $(0 \%$ clove oil) at 7,5 , or $2 \mathrm{~d}$ before transplant, or soil around the seedlings was drenched at transplant $(0 \mathrm{~d})$. Seedlings were harvested after $8 \mathrm{~d}$.

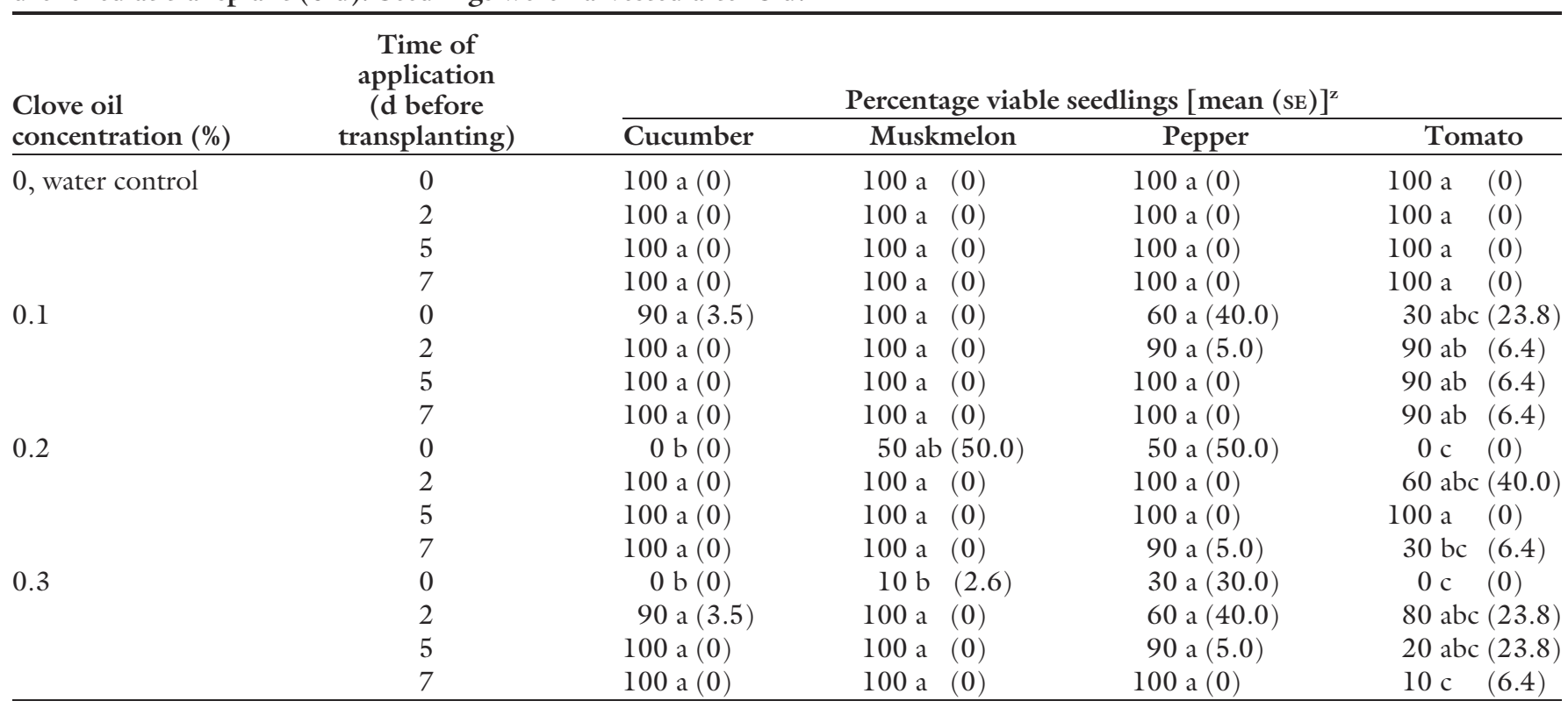

${ }^{2}$ Values within a column followed by the same letter are not significantly different; $\alpha=0.05$. 
(Figs. 1 and 2). These parameters demonstrated differences among some treatments even when plants remained alive. As with plant viability, responses were not the same in all of the plant species. Cucumber shoots were the least affected-the heights of surviving seedlings were not significantly reduced by any clove oil treatment, and a weight reduction occurred only with $0.3 \%$ clove oil applied $2 \mathrm{~d}$ before transplant (Fig. 1A). Muskmelon, pepper, and tomato shoot growth was decreased by at- transplant $(0 \mathrm{~d})$ drenches with $0.1 \%$ clove oil (Figs. 1B and 2, A and B). Although some muskmelon and pepper plants survived $0 \mathrm{~d}$ treatment with $0.2 \%$ and $0.3 \%$ clove oil, shoots were smaller than those from the water controls (Figs. 1B and 2A). Shoots of all three plants were also smaller with some of the other $0.2 \%$ and $0.3 \%$ treatments (Figs. $\mathrm{IB}$ and $2, \mathrm{~A}$ and B), even though plant viability was not always affected.

To determine whether clove oil could be applied in a manner that

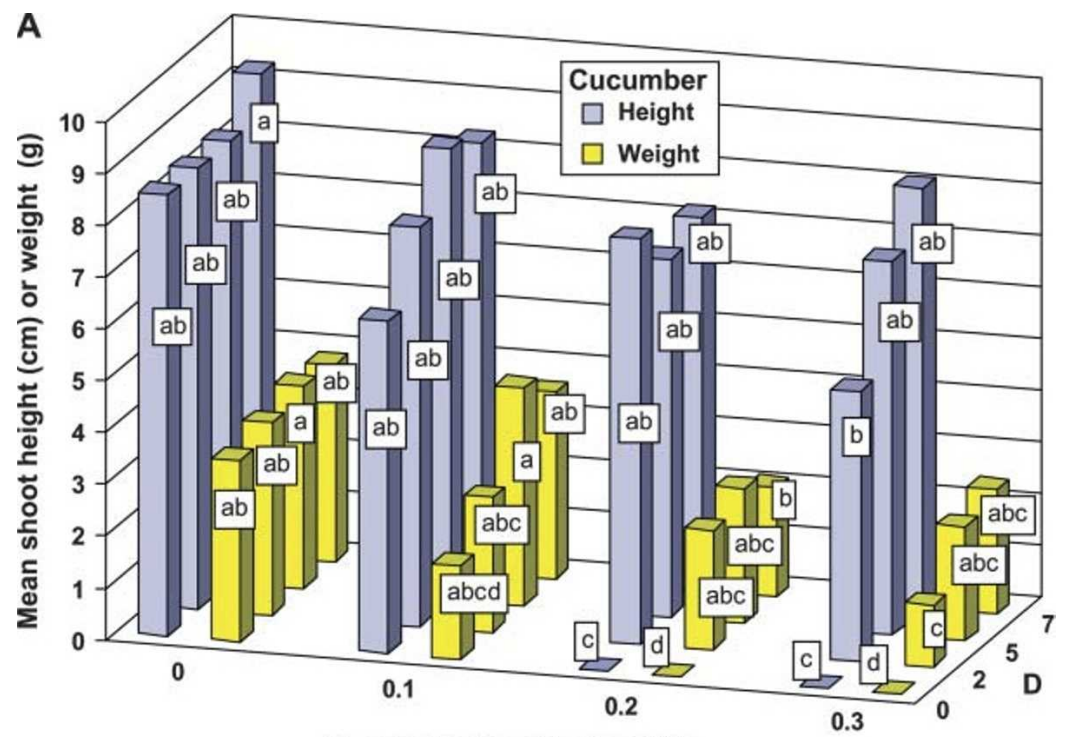

Clove oil concentration (\%)

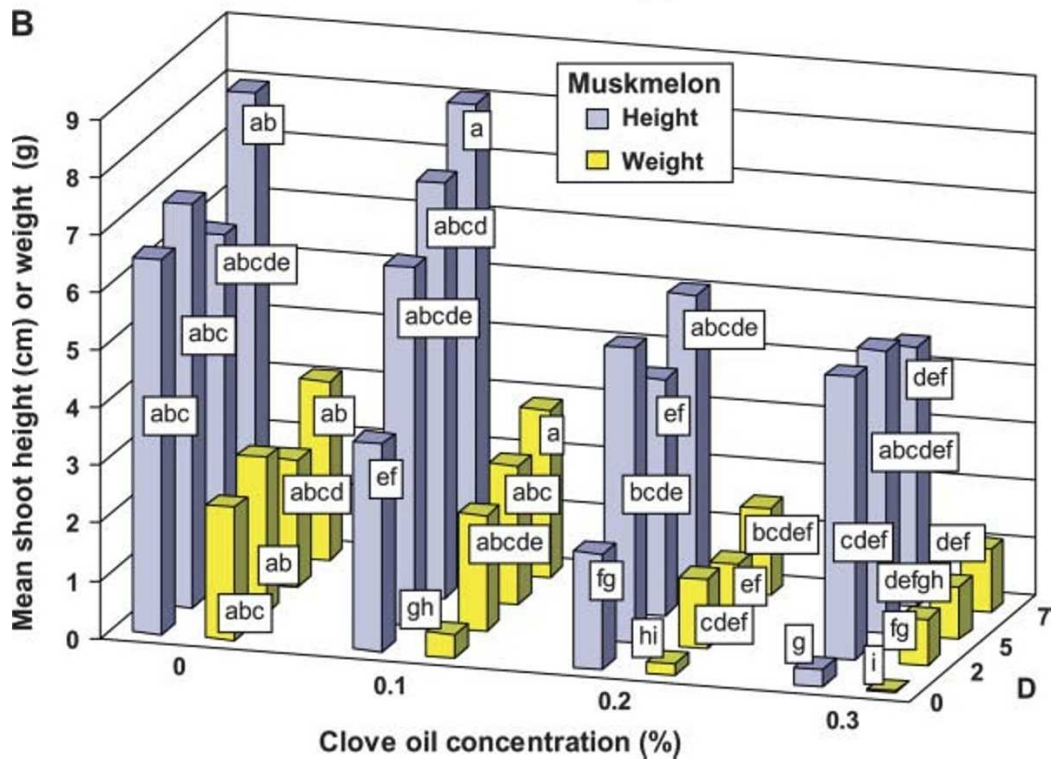

Fig. 1. Effects of various clove oil concentrations and soil application times $(\mathrm{D}=$ number of days that clove oil was applied before transplant) on (A) cucumber and (B) muskmelon shoot heights $(1 \mathrm{~cm}=0.3937 \mathrm{inch})$ and fresh weights $(1 \mathrm{~g}=\mathbf{0 . 0 3 5 3}$ $\mathrm{oz})$. Seedlings at the one-leaf stage were transplanted into soil that had been drenched with clove oil or a water control at transplant $(0 \mathrm{~d})$, or treated 2,5 , or $7 \mathrm{~d}$ before transplant. Seedlings were harvested after $8 \mathrm{~d}$. Values for shoot height or fresh weight followed by the same letter are not significantly different at $\alpha=0.05$.

was nematotoxic but not phytotoxic, cucumber was selected for further study. Because the higher clove oil concentrations tended to exhibit the most phytotoxicity to the tested crop species, $0.20 \%$ and lower $(0.15 \%$ and $0.10 \%)$ clove oil concentrations applied $7 \mathrm{~d}$ before transplant were used for investigating the suppression of RKN populations. The effects on cucumber plant vigor are presented in Table 2 and on nematode population numbers in Fig. 3.

No clove oil concentration consistently resulted in smaller shoots than the water control (Table 2). The $0.20 \%$ clove oil treatment without nematodes, and the carrier control treatment with nematodes, did not affect shoot length in either trial. All other concentrations reduced shoot heights in one trial but not the other trial, with concomitant reductions in shoot fresh weights. Lower shoot weights compared with water controls were recorded in both trials from nematode-inoculated plants with two treatments: the carrier control and the $0.10 \%$ clove oil. These results differed somewhat from the earlier phytotoxicity trials with cucumber seedlings harvested 8 d after transplant in which there was no decrease in cucumber shoot heights or weights with $0.1 \%$ or $0.2 \%$ clove oil applied $7 \mathrm{~d}$ before transplant compared with the water control (Fig. 1A). However, the main difference in shoot size in the nematode-suppression study on cucumber was that plants without nematodes had greater shoot heights in Trial 1 and greater weights in both trials than plants with nematodes.

The opposite result was recorded with root fresh weights-plants inoculated with nematodes had heavier roots than plants without nematodes. There were no consistent differences in root weights among clove oil treatments-no concentration affected root weights in Trial 1. In Trial 2, the heaviest roots were recorded from the $0.15 \%$ clove oil treatment without nematodes and from carrier control plants with nematodes (Table 2).

Effects of clove oil on RKN population densities on cucumber roots varied greatly between the two trials. In Trial 1, the greatest numbers of eggs per gram of root were recorded from the water and carrier control treatments and from the 
A

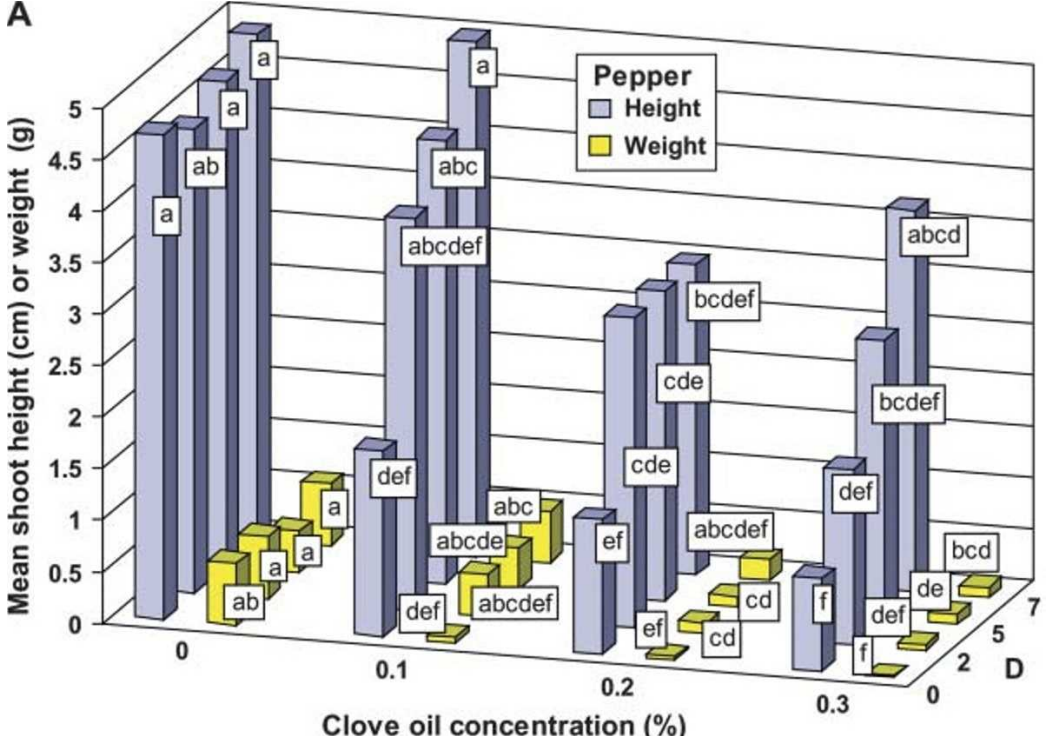

Clove oil concentration (\%)

B

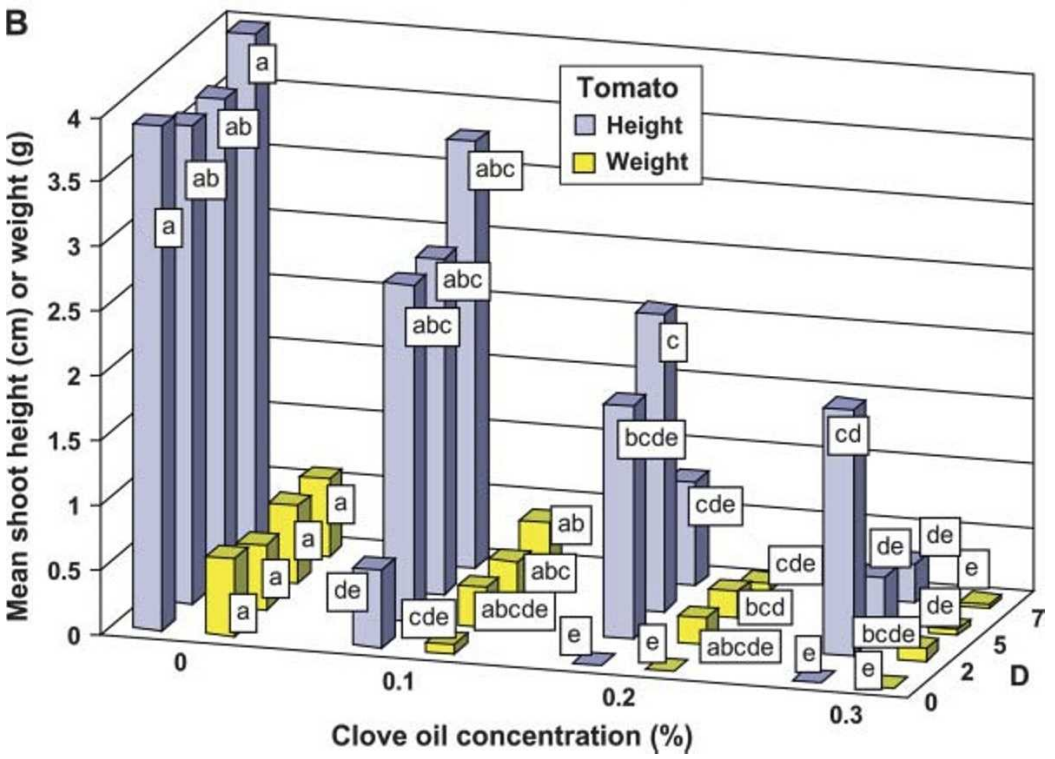

Fig. 2. Effects of various clove oil concentrations and soil application times $(D=$ number of days that clove oil was applied before transplant) on (A) pepper and (B) tomato shoot heights $(1 \mathrm{~cm}=0.3937 \mathrm{inch})$ and fresh weights $(1 \mathrm{~g}=0.0353 \mathrm{oz})$. Seedlings at the one-leaf stage were transplanted into soil that had been drenched with clove oil or a water control at transplant $(0 \mathrm{~d})$, or treated 2,5 , or $7 \mathrm{~d}$ before transplant. Seedlings were harvested after $8 \mathrm{~d}$. Values for shoot height or fresh weight followed by the same letter are not significantly different at $\alpha=0.05$.

highest clove oil concentration, $0.20 \%$ (Fig. 3). The lowest clove oil concentrations, $0.10 \%$ and $0.15 \%$, suppressed nematode populations when compared with the carrier control; populations were reduced by $36.8 \%$ and $36.0 \%$, respectively.

The results were quite different in Trial 2 (Fig. 3). The application of water and of carrier controls resulted in fewer nematodes than treatment with any of the tested clove oil concentrations, with the lowest RKN populations recorded from the carrier control treatment. When compared with the $0.10 \%$ clove oil concentration, nematode numbers on the water control and carrier control plants were reduced by $41.3 \%$ and $63.4 \%$, respectively. Reductions were even greater compared with application of $0.20 \%$ clove oil (Fig. 3).

\section{Discussion}

Some of the tested clove oil treatments were phytotoxic to cucumber, muskmelon, pepper, and tomato seedlings. The effects varied with plant species, clove oil concentration, and application time. Drenching the soil with clove oil at transplant tended to result in more adverse effects than a pretransplant soil application. Tomato seedling viability was the most affected, whereas viable cucumber seedlings showed the best shoot growth compared with the other plant types. For this reason, cucumber was used to determine efficacy of nonphytotoxic clove oil applications for suppressing RKN population densities. Clove oil applications of $0.10 \%$, $0.15 \%$, and $0.20 \%$ were not sufficient to consistently or greatly reduce nematode populations on cucumber roots. In one trial, there were fewer nematodes on the control plants then on the clove oil-treated plants. In the other trial, some nematotoxicity was recorded with $0.10 \%$ and $0.15 \%$ clove oil applications, but the nematode populations were not reduced more than $36 \%$ to $37 \%$ compared with the water controls. Clove oil application also sometimes resulted in smaller shoots than treatment with the water control.

Previous studies with clove oil have indicated that phytotoxic effects can occur and are dependent upon factors such as plant species, oil concentrations tested, volume of clove oil formulation applied, and the size of plants (Boyd and Brennan, 2006). Some phytotoxic effects on muskmelon and tomato, two of the plants used in our study, were reported when clove oil or its main constituent eugenol were applied for plant pathogen suppression. When $1 \%, 5 \%$, and $10 \%$ aqueous emulsions of clove extracts (containing 70\% clove oil) were applied 1 week before muskmelon planting for management of the fungus Fusarium oxysporum (causal agent of Fusarium wilt disease), the $10 \%$ formulation caused stunting and other phytotoxic symptoms (Bowers and Locke, 2000). In a study of essential oils as nematicides, $250 \mathrm{mg}$ of eugenol per kilogram of soil applied to the soil 1 week before transplant of tomato seedlings was not phytotoxic if the bags were left open. If the tomatoes were planted right after the eugenol application, the plants died (Walker and Melin, 1996). In addition, some decrease in shoot dry weight was recorded with 1000 and $1500 \mathrm{mg}$ of eugenol per 
Table 2. Effects of various clove oil concentrations on cucumber plant vigor, with (+) and without (-) inoculation of southern root-knot nematode (RKN). The clove oil and controls were applied $7 \mathrm{~d}$ before seedling transplant. Plants were harvested 5 weeks after transplant.

\begin{tabular}{|c|c|c|c|c|c|c|}
\hline \multirow{2}{*}{$\begin{array}{l}\text { Clove oil } \\
\text { concentration (\%) }\end{array}$} & \multicolumn{2}{|c|}{ Mean shoot ht $(\mathrm{sE})(\mathrm{cm})^{\mathrm{z}}$} & \multicolumn{2}{|c|}{ Mean shoot fresh wt $(\mathrm{SE})(\mathrm{g})^{\mathrm{y}}$} & \multicolumn{2}{|c|}{ Mean root fresh wt $(\mathrm{SE})(\mathrm{g})$} \\
\hline & Trial l & Trial 2 & Trial 1 & Trial 2 & Trial 1 & Trial 2 \\
\hline \multicolumn{7}{|l|}{$(-) \mathrm{RKN}$} \\
\hline 0 , carrier control & $103.1 \mathrm{bc}(7.3)$ & $126.2 \mathrm{abc}(3.3)$ & $48.3 \mathrm{c} \quad(3.6)$ & $61.6 \mathrm{ab}(1.6)$ & 20.5 a $(1.5)$ & $19.7 \mathrm{bc}(0.8)$ \\
\hline 0.10 & $113.5 \mathrm{abc}(9.3)$ & $101.7 \mathrm{~d} \quad(9.6)$ & $64.0 \mathrm{ab}(5.9)$ & $56.1 \mathrm{~b} \quad(2.7)$ & $22.2 \mathrm{a}(1.5)$ & $17.8 \mathrm{bc}(0.9)$ \\
\hline 0.15 & 95.5 c $(10.9)$ & $130.7 \mathrm{ab} \quad(12.8)$ & $53.8 \mathrm{bc}(3.8)$ & $65.7 \mathrm{a} \quad(2.5)$ & $19.5 \mathrm{a}(1.1)$ & $21.1 \mathrm{ab}(0.7)$ \\
\hline RKN treatments & $113.9 \mathrm{~A}^{\mathrm{w}}(9.2)$ & $120.9 \mathrm{~A}(8.2)$ & $59.6 \mathrm{~A}(5.0)$ & $61.6 \mathrm{~A}(2.6)$ & $20.8 \mathrm{~B}(1.3)$ & $18.6 \mathrm{~B}(0.9)$ \\
\hline \multicolumn{7}{|l|}{$\overline{(+) \mathrm{RKN}}$} \\
\hline 0 , water control & $113.2 \mathrm{a}$ & $145.0 \mathrm{a}$ & $57.4 \mathrm{a} \quad(2.5)$ & $71.5 \mathrm{a} \quad(2.7)$ & $24.0 \mathrm{a}(1.0)$ & 29.7 b $\quad(0.9)$ \\
\hline 0 , carrier control & $95.7 \mathrm{a}$ & $129.0 \mathrm{abc}(6.7)$ & $47.6 \mathrm{~b} \quad(3.2)$ & $61.4 \mathrm{~b} \quad(2.0)$ & 24.0 a $(1.7)$ & $33.7 \mathrm{a} \quad(2.8)$ \\
\hline 0.10 & $95.7 \mathrm{a}$ & $106.2 \mathrm{de} \quad(6.5)$ & $42.5 \mathrm{~b} \quad(2.2)$ & $49.3 \mathrm{~cd}(3.1)$ & $26.2 \mathrm{a}(1.5)$ & $28.9 \mathrm{~b} \quad(1.2)$ \\
\hline
\end{tabular}

$1 \mathrm{~cm}=0.3937$ inch.

${ }^{y} 1 \mathrm{~g}=0.0353 \mathrm{oz}$.

'For each trial, lower case significance letters are comparable in a single column, within $(+) \mathrm{RKN}$ treatments and within (-)RKN treatments, but not between plants with and without RKN. Values followed by the same letter are not significantly different according to Tukey's adjusted for multiple comparisons at $P<0.05$

wFor each trial, upper case significance letters are only comparable in a single column for the means for all treatments. Means followed by the same letter are not significantly different according to Tukey's adjusted for multiple comparisons at $P<0.05$.

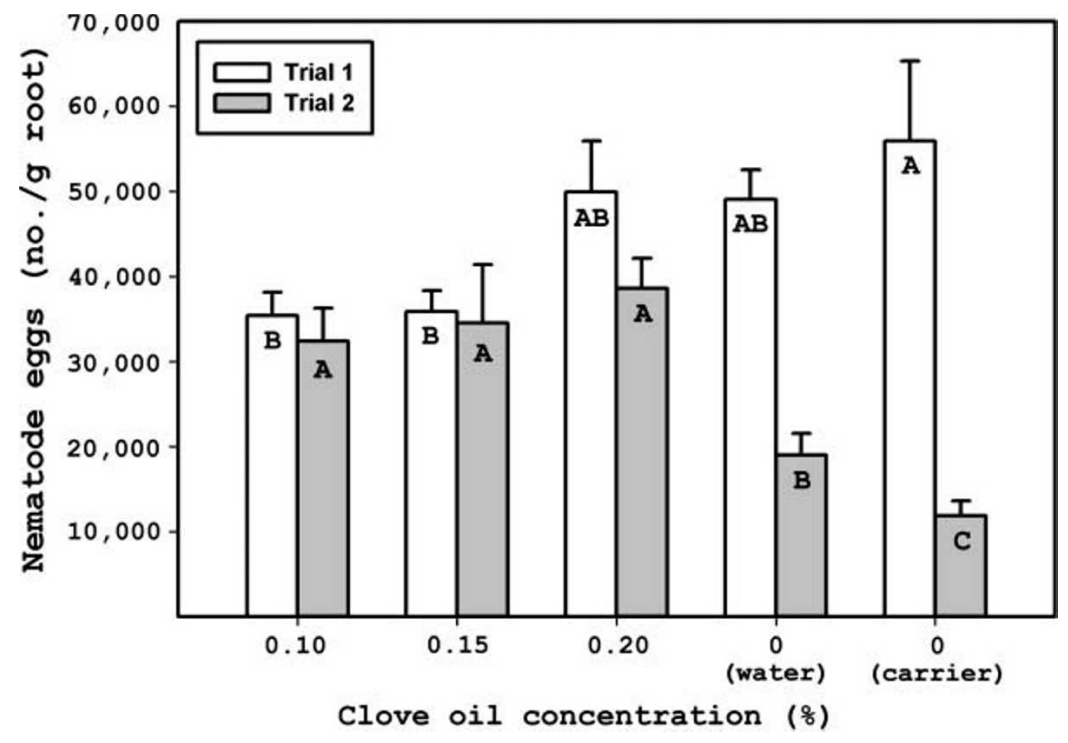

Fig. 3. Effects of various clove oil concentrations on southern root-knot nematode population densities on cucumber roots. Seedlings were transplanted into soil that had been treated with clove oil or a control and inoculated with nematode eggs $7 \mathrm{~d}$ before transplant. Nematode population densities were recorded 5 weeks after transplant ( $1 \mathrm{egg} / \mathrm{g}=28.3495 \mathrm{eggs} / \mathrm{oz}$ ). Values for Trial 1 or Trial 2 followed by the same letter are not significantly different according to Tukey's adjusted for multiple comparisons at $P<0.05$.

kilogram of soil on tomato inoculated with peanut RKN (Meloidogyne arenaria) (Walker and Melin, 1996). By comparison, the concentrations used in our greenhouse study with tomato were equivalent to 100 to $300 \mathrm{mg}$ of clove oil per kilogram of soil. This was about 76 to $230 \mathrm{mg}$ of eugenol per kilogram of soil [based on the measured amounts of eugenol in the bottles of clove oil sampled from our laboratory assays, which were $74.6 \%$ to $78.6 \%$ eugenol (Meyer et al., 2008)]. As in the Walker and Melin study (1996), all of the clove oil concentrations that we tested resulted in some phytotoxicity when applied at the time of tomato transplant. The highest application rates used in our study were phytotoxic to tomato when applied to soil $7 \mathrm{~d}$ before planting and kept in sealed bags, although the clove oil concentration equivalent to $76 \mathrm{mg}$ of eugenol per kilogram of soil was not phytotoxic when applied 2, 5, or $7 \mathrm{~d}$ before transplant.

Laboratory assays have demonstrated nematotoxicity of clove oil to plant-parasitic nematodes, including seed gall, foliar, pinewood, spiral, pigeon pea cyst, lance, needle, brazilian root-knot, javanese root-knot, lesion, citrus, and american dagger nematodes (Anguina tritici, Apbelenchoides fragariae, Bursaphelenchus xylophilus, Helicotylenchus indicus, Heterodera cajani, Hoplolaimus indicus, Longidorus sp., Meloidogyne exigua, Meloidogyne javanica, Pratylenchus sp., Tylenchulus semipenetrans, and Xiphinema americanum, respectively) (Jagdale and Grewal, 2002; Pandey and Dwivedi, 2000; Park et al., 2005; Salgado and Campos, 2003a; Sangwan et al., 1990). Laboratory studies with southern 
RKN, the species used in our study, have also reported loss of viability with exposure to clove oil or eugenol (Chatterjee et al., 1982; Gokte et al., 1991; Leela and Ramana, 2000; Meyer et al., 2008). For example, eugenol was active against southern RKN J2 at rates ranging from 100 to $500 \mathrm{ppm}[0.01 \%$ to $0.05 \%$ (Gokte et al., 1991)]. The mean effective clove oil concentrations that reduced egg hatch and $\mathrm{J} 2$ viability by $90 \%$ in microwell assays were $0.104 \%$ and $0.151 \%$ clove oil, respectively, and the mean effective concentration that reduced $\mathrm{J} 2$ recovery from soil by $50 \%$ was $0.192 \%$ clove oil (Meyer et al., 2008). Despite the levels of nematotoxicity recorded in these assays (Meyer et al., 2008), application of $0.2 \%$ clove oil in the same formulation did not reduce nematode population densities by $50 \%$ or more on cucumber, even though the clove oil was initially applied to the more sensitive egg stage. Also, higher root weights were reported from plants treated with nematodes, indicating that $\mathrm{RKN}$ populations from all treatments were sufficient to affect root weights.

Few tests have been conducted with clove oil or eugenol against RKN species on plants to compare with this study. As with phytotoxicity, nematicidal effects of clove oil undoubtedly depend on many variables, including formulation, concentration, time of application, soil type, and host plant. In a test for eugenol as a potential systemic nematicide, 10 $\mathrm{mL}$ of eugenol at 0.2 and $0.5 \mathrm{~mL} \cdot \mathrm{L}^{-1}$ $(0.02 \%$ and $0.05 \%$ aqueous emulsion; higher rates were phytotoxic) were sprayed onto hibiscus (Hibiscus esculentus) leaves, and $0.5 \mathrm{~mL} \cdot \mathrm{L}^{-1}$ eugenol were drenched into soil around other hibiscus plants (Bala and Sukul, 1987). The numbers of southern RKN galls and J2 in soil and roots were reduced with eugenol treatment, and shoot lengths and weights and root lengths were increased (Bala and Sukul, 1987). Root weights were greatest on nematode-inoculated plants without eugenol. In the Walker and Melin (1996) study, eugenol was applied to steamed soil at rates of 250 , 500,1000 , and $1500 \mathrm{mg} \cdot \mathrm{kg}^{-1}$ soil, and southern $\mathrm{RKN}$ and peanut RKN (Meloidogyne arenaria) eggs were exposed to the oil for 1 week before transplant of tomato seedlings. Reductions in galling of roots by nematodes were not significant; egg numbers were not recorded. They did not test clove oil, which contains more than one compound that is active against nematodes. Clove plant extracts were also tested in the greenhouse against southern RKN on bean (Phaseolus vulgaris) and brazilian RKN on coffee (Coffea arabica). For each plant, $30 \mathrm{~mL}$ of extract was applied at 5\%, 10\%, and 20\% (coffee) or $5 \%$ and $20 \%$ (bean). Southern RKN population densities were suppressed on bean with clove oil, but brazilian RKN population densities on coffee increased, even though the nematode was sensitive to clove oil in laboratory assays (Salgado and Campos, 2003a, 2003b).

In this greenhouse investigation of clove oil as a potential nematicide, phytotoxicity and nematotoxicity were variable. In the cucumber study, phytotoxic effects were observed some of the time at the lowest tested clove oil concentration. Effects on nematode populations were extremely different between the two trials; therefore, the clove oil formulation was not effective for suppressing nematode population densities on cucumber. Despite the interest in clove oil as a bio-based pesticide, these results do not encourage use of the tested clove oil formulation or the application times for managing southern RKN on vegetable crop plants.

\section{Literature cited}

Bainard, L.D., M.B. Isman, and M.K. Upadhyaya. 2006. Phytotoxicity of clove oil and its primary constituent eugenol and the role of leaf epicuticular wax in the susceptibility to these essential oils. Weed Sci. 54:833-837.

Bala, S.K. and N.C. Sukul. 1987. Systemic nematicidal effect of eugenol. Nematropica 17:219-222.

Beg, A.Z. and I. Ahmad. 2002. In vitro fungitoxicity of the essential oil of Syzygium aromaticum. World J. Microbiol. Biotechnol. 18:313-315.

Bowers, J.H. and J.C. Locke. 2000. Effect of botanical extracts on the population density of Fusarium oxysporum in soil and control of fusarium wilt in the greenhouse. Plant Dis. 84:300-305.

Bowers, J.H. and J.C. Locke. 2004. Effect of formulated plant extracts and oils on population density of Phytophthora nicotianae in soil and control of phytophthora blight in the greenhouse. Plant Dis. 88:11-16.

Boyd, N.S. and E.B. Brennan. 2006. Burning nettle, common purslane, and rye response to a clove oil herbicide. Weed Technol. 20:646-650.

Boyd, N.S., E.B. Brennan, and S.A. Fennimore. 2006. Stale seedbed techniques for organic vegetable production. Weed Technol. 20:1052-1057.

Chatterjee, A., N.C. Sukul, S. Laskar, and S. Ghoshmajumdar. 1982. Nematicidal principles from two species of Lamiaceae. J. Nematol. 14:118-120.

Chitwood, D.J. 2002. Phytochemical based strategies for nematode control. Annu. Rev. Phytopathol. 40:221-249.

Cowan, M.M. 1999. Plant products as antimicrobial agents. Clin. Microbiol. Rev. 12:564-582.

Dorman, H.J.D. and S.G. Deans. 2000. Antimicrobial agents from plants: Antibacterial activity of plant volatile oils. J. Appl. Microbiol. 88:308-316.

Gokte, N., M.L. Maheshwari, and V.K. Mathur. 1991. Nematicidal activity of few essential oils against root-knot and cyst nematode species. Indian J. Nematol. 21:123-127.

Isman, M.B. 2000. Plant essential oils for pest and disease management. Crop Prot. 19:603-608.

Jagdale, G.B. and P.S. Grewal. 2002. Identification of alternatives for the management of foliar nematodes in floriculture. Pest Mgt. Sci. 58:451-458.

Kishore, G.K., S. Pande, and S. Harish. 2007. Evaluation of essential oils and their components for broad-spectrum antifungal activity and control of late leaf spot and crown rot disease in peanut. Plant Dis. 91:375-379.

Koenning, S.R., C. Overstreet, J.W. Noling, P.A. Donald, J.O. Becker, and B.A. Fortnum. 1999. Survey of crop losses in response to phytoparasitic nematodes in the United States for 1994. J. Nematol. (Suppl.) 31:587-618.

Leela, N.K. and K.V. Ramana. 2000. Nematicidal activity of the essential oil of allspice (Pimenta dioica L. Merr.). J. Plant Biol. 27:75-76.

Meyer, S.L.F., D.K. Lakshman, I.A. Zasada, B.T. Vinyard, and D.J. Chitwood. 2008. Dose-response effects of clove oil from Syzygium aromaticum on the rootknot nematode Meloidogyne incognita. Pest Mgt. Sci. 64:223-229. 


\section{Research Reports}

Montes-Belmont, R. and M. Carvajal. 1998. Control of Aspergillus flavus in maize with plant essential oils and their components. J. Food Prot. 61:616-619.

Pandey, R.C. and B.K. Dwivedi. 2000. Comparative study of different plant extracts for their nematicidal potential. Curr. Nematol. 11:39-43.

Park, I.K., J.Y. Park, K.H. Kim, K.S. Choi, I.H. Choi, C.S. Kim, and S.C. Shin. 2005. Nematicidal activity of plant essential oils and components from garlic (Allium sativum) and cinnamon (Cinnamomum verum) oils against the pine wood nematode (Bursaphelenchus xylophilus). Nematology 7:767-774.

Salgado, S.M.L. and V.P. Campos. 2003a. Hatching and mortality of Meloidogyne exigua in extracts and in natural products. Fitopatol. Bras. 28:166-170.
Salgado, S.M.L. and V.P. Campos $2003 \mathrm{~b}$. Effects of natural extracts on pathogenicity and reproduction of Meloidogyne exigua in coffee and Meloidogyne incognita race 3 in the common bean Nematologia Brasileira 27:41-48.

Sangwan, N.K., B.S. Verma, K.K. Verma, and K.S. Dhindsa. 1990. Nematicidal activity of some essential plant oils. Pestic. Sci. 28:331-335.

Tworkoski, T. 2002. Herbicide effects of essential oils. Weed Sci. 50:425-431.

Waliwitiya, R., M.B. Isman, R.S. Vernon, and A. Riseman. 2005. Insecticidal activity of selected monoterpenoids and rosemary oil to Agriotes obscurus (Coleoptera: Elateridae). J. Econ. Entomol. 98:1560-1565.

Walker, J.T. and J.B. Melin. 1996. Mentha $\times$ piperita, Mentha spicata and effects of their essential oils on Meloidogyne in soil. J. Nematol. (Suppl.) 28:629-635

Walter, J.F., J.C. Locke, and M.C. Normoyle. 1997. Clove oil as a plant fungicide. U.S. Patent No. 5,679,351. U.S. Patent and Trademark Office, Washington, DC.

Walter, M., M.V. Jaspers, K. Eade, C.M. Frampton, and A. Stewart. 2001. Control of Botrytis cinerea in grape using thyme oil. Austral. Plant Pathol. 30:21-25.

Yang, Y.C., S.H. Lee, W.J. Lee, D.H. Choi, and Y.J. Ahn. 2003. Ovicidal and adulticidal effects of Eugenia caryophyllata bud and leaf oil compounds on Pediculus capitis. J. Agr. Food Chem. 51:4884-4888. 